\title{
La política migratoria mexicana después de IRCA
}

\author{
Francisco Alba*
}

El tema de las respuestas mexicanas, en particular las gubernamentales, acerca del fenómeno de la migración de mexicanos hacia Estados Unidos ha adquirido relevancia a partir de los cambios legislativos estadunidenses en materia inmigratoria iniciados en 1986 y actualizados en 1996 y de la intensificación de manífestaciones antinmigrantes y xenófobas por amplios sectores de la sociedad de aquel país. En este trabajo se revisa brevemente la politica mexicana que se sigue con posterioridad a la terminación de los programas de braceros y, con más detenimiento, se analizan los cambios en la postura gubernamental a raíz de la aprobación, en 1986, de la Ley de Reforma y Control de la Inmigración hasta la reciente Ley de Reforma de la Inmigración Ilegal y de Responsabilidad del Inmigrante de 1996, explorándose algunas de las implicaciones de estos cambios y de la política migratoria mexicana actual.

\section{Introducción}

Entre los temas tradicionales de discusión ante la opinión pública mexicana respecto del fenómeno migratorio hacia Estados Unidos -sus causas, efectos y política estadunidense-, en años recientes se ha añadido el de la política migratoria del gobierno mexicano. Este tópico surge con intensidad particularmente a raíz de debates y cambios legislativos estadunidenses, o a raíz de algún incidente migratorio, como el ocurrido en Riverside. ${ }^{1}$ En esas ocasiones se externa frecuentemente la idea de que el gobierno mexicano carece de una política frente al fenómeno de la emigración, o bien se expresa un desacuerdo con la estrategia o las acciones tomadas por éste para

* Profesor-investigador del Centro de Estudios Demográficos y de Desarrollo Urbano de El Colegio de México.

${ }^{1}$ Los hechos que constituyen el incidente de Riverside tuvieron lugar el 1 de abril de 1996 en el condado de Riverside, California. Una persecución de inmigrantes mexicanos (20) terminó en una paliza propinada a dos de ellos -una mujer y un hombre-junto al vehículo en que eran transportados. Lo novedoso del incidente fue que las escenas de la persecución y de los golpes fueron captadas por una estación de televisión y trasmitidas, casi de inmediato tanto dentro como fuera de Estados Unidos. Las declaraciones y reacciones que este incidente provocó en México ocuparon los espacios principales - primeras planas y encabezados de ocho columnas-de buena parte de la prensa mexicana. Para una descripción y análisis de las reacciones que provocó el incidente de Riverside, véase Fernández de Castro (1998). 
hacer frente a eventos asociados con dicho fenómeno. En cambio, las declaraciones y reacciones gubernamentales suelen afirmar lo contrario: se tiene una política y ésta se aplica con consistencia.

Una somera revisión de la prensa nacional de 1996 muestra que en abril la cobertura del tema migratorio se incrementó significativamente - a raíz del incidente de Riverside-con numerosos artículos y declaraciones en torno a la política migratoria del gobierno mexicano. De la revisión de las notas periodísticas se desprende, en efecto, que sobresale un tono de reproche por lo que se considera inacción o tibieza de las medidas y estrategias adoptadas; en ocasiones la prensa se cuestiona si existe una política gubernamental bien definida, y si se relaciona el fenómeno migratorio con los efectos de la política económica del gobierno. No es infrecuente que el cuerpo central de las notas se base en opiniones, declaraciones y entrevistas de actores políticos. Obviamente, las posturas críticas suelen provenir de miembros de los partidos fuera del gobierno, de académicos y de organizaciones no gubernamentales, aunque no exclusivamente. La prensa retoma también, en una proporción casi similar, declaraciones y notas informativas que explican, difunden y defienden la política gubernamental, las posturas asumidas y las acciones llevadas a cabo. ${ }^{2}$

A través de este intercambio de opiniones y declaraciones en la prensa sobre la cuestión migratoria y la política mexicana, se observa una coincidencia e insistencia en hacer de la defensa de los derechos humanos el tema central de la política migratoria. Sin embargo, la revisión de esa multitud de declaraciones, pronunciamientos, explicaciones, aclaraciones, reclamos y exigencias también deja la impresión de que no existe un conocimiento preciso y aceptablemente comprensivo sobre la política migratoria mexicana. La tónica de reduccionismo hacia la defensa de los derechos de los migrantes y la denuncia contra la política y las medidas de Estados Unidos es omnipresente. Este artículo ofrece algunos elementos de información con el propósito de contribuir a ampliar el conocimiento y la discusión acerca de cuál es y cuál ha sido la política mexicana sobre la migración hacia Estados Unidos.

${ }^{2} \mathrm{La}$ revisión de la prensa nacional se refiere a dos periódicos - El Financiero y La Jornada - de la ciudad de México. La política de Estados Unidos es, desde luego, otro de los principales tópicos generalizado de interés para la prensa nacional. 
Las fuentes de información para la elaboración de este trabajo son producto de una revisión de la literatura sobre política de migración y las declaraciones e intervenciones de los legisladores mexicanos contenidas en los comunicados y memorias de las reuniones interparlamentarias México-Estados Unidos realizadas desde 1961 (Congreso de la Unión, varios años). Dada la composición del Legislativo, se supone que las declaraciones de la delegación mexicana refilejan adecuadamente, al menos hasta años recientes, las posiciones gubernamentales. Se utilizan declaraciones de funcionarios gubernamentales aparecidas en la prensa nacional en años recientes, particularmente de 1995 en adelante. El trabajo también se basa en el informe y documentación relacionada con el Estudio Binacional México-Estados Unidos sobre Migración, del cual formé parte, particularmente con el capítulo correspondiente a las respuestas frente al fenómeno migratorio. ${ }^{3}$

Además de esta introducción, otras tres partes constituyen este trabajo. En la segunda parte se pasa revista brevemente a la política migratoria mexicana que se desarrolla en 1965 después de la terminación de los programas de braceros y hasta la aprobación de la Ley de Reforma y Control de la Inmigración (IRCA, por sus siglas en inglés) en 1986. En la tercera parte se presenta un análisis de los cambios en la postura gubernamental mexicana con posterioridad a IRCA. En la cuarta y última parte se exploran algunas de las implicaciones de la política actual para hacerle frente al fenómeno migratorio.

Antecedentes: las políticas migratorias antes de IRCA

En comparación con la política de inmigración, la política de emigración no tiene -ni en México, ni en la mayoría de los países- las expresiones jurídicas que suele tener aquélla. Sin embargo, existen en el caso mexicano disposicionesijurídicas que se han interpretado como relacionadas con el tema de la política emigratoria. Una de las

\footnotetext{
${ }^{3}$ Algunas de las ideas contenidas en este trabajo encontraron expresión en el documento de Sidney Weintraub, Francisco Alba, Rafael Fernández de Castro y Manuel García y Griego, "Responses to Migration Issues", que fue elaborado para el Estudio Binacional (Weintraub et al., 1998). Se reconoce la deuda que el autor ha adquirido con los coautores del documento mencionado. También se expresa un reconocimiento a Georgina Rojas y Silvia Giorguli por la asistencia de investigación prestada en distintas etapas de la elaboración del presente trabajo.
} 
más importantes se refiere a las garantías constitucionales de libre tránsito de los ciudadanos por el territorio nacional, ${ }^{4}$ lo que suele interpretarse como la imposibilidad gubernamental de prevenir la emigración. Esta interpretación - que ha adquirido condición de consenso nacional- tiene en su contra la existenciaijurídica de requisitos formales de salida del territorio nacional. Por un lado, la salida debe ser por lugares específicos así designados para ello; por otro, al igual que en la mayoría de los países, se requiere documentación adecuada para entrar y salir del país. ${ }^{5}$ En la práctica, estos requisitos formales son frecuentemente ignorados o resultan irrelevantes, sobre todo cuando las salidas ocurren en sitios apartados, lejanos de los lugares de salida designados. ${ }^{6}$

La interpretación anterior cuenta también con un antecedente contrario cuando, durante los programas de braceros, el gobierno mexicano anunció su intención de efectuar acciones de patrullaje de la frontera y de hecho utilizó selectivamente al ejército y a la policía para prevenir el reclutamiento unilateral de braceros por parte de Estados Unidos (García y Griego, 1998; García y Griego y Verea Campos, 1988: 108). En la actualidad, la fracción IV del artículo 64 del Reglamento de la Ley General de Población autoriza a la Secretaría de Gobernación a ejercer "en los lugares no autorizados al tránsito internacional la vigilancia que considere necesaria para impedirlo".

Existen también disposiciones legislativas respecto a la protección de los mexicanos (emigrantes) en el extranjero y, además, estipulaciones sobre las condiciones de trabajo de los trabajadores migratorios, incluidos los indocumentados, y la prevención del tráfico ilícito de personas por parte de transportistas, reclutadores, enganchadores y similares. ${ }^{7}$

${ }^{4}$ La mención al derecho de libre tránsito se incluye en la sección de garantías individuales, artículo 11 de la Constitución Política de los Estados Unidos Mexicanos. Ahí queda consignado que el ejercicio de este derecho está subordinado a las facultades de la autoridad judicial y de las autoridades administrativas de acuerdo con las leyes específicas.

${ }^{5}$ Véase los artículos 10 y 11 de la Ley General de Población y 71 de su Reglamento (México, Leyes, 1996).

6 Dadas las disposiciones vigentes, los "indocumentados" no lo son sólo frente a Estados Unidos, los son también frente a México.

${ }^{7}$ Véase el artículo 79 de la Ley General de Población y artículos 55, fracción III, inciso $b, 71,138$ y 139 de su Reglamento (México, Leyes, 1996). Las reformas y adiciones de la Ley General de Población del 8 de noviembre de 1996 incrementaron las penas por el tráfico de personas. 
En México se cuenta, adicionalmente con otra expresión jurídica muy importante respecto a la política migratoria gubernamental: la plasmada en los acuerdos bilaterales entre México y Estados Unidos para el manejo de los flujos laborales (los programas de braceros) que estuvieron vigentes entre 1942 y 1964 . La existencia de esos acuerdos no significa, desde luego, que se haya promovido o alentado la emigración, pero sí la aceptación de la emigración como una situación real. Las disposiciones sobre contratación, condiciones laborales, etc., contenidas en dichos acuerdos constituyen también elementos de la política migratoria de ese periodo. Desde 1965, esos acuerdos ya no existen, si bien la emigración ha continuado. ¿Cuáles son, con posterioridad a 1965 , las políticas, posiciones o estrategias frente al fenómeno migratorio?

La existencia de los programas de braceros, de 1942 a 1964, ha tenido importantes repercusiones sobre la política gubernamental mexicana frente al fenómeno migratorio, ya que ha obligado, casi constantemente, a la administración a manifestarse respecto a la conveniencia o no de contar con algún tipo de convenio migratorio como instrumento de manejo de los flujos de trabajadores mexicanos a Estados Unidos. De hecho, la renovación de los convenios migratorios fue uno de los elementos centrales de la política migratoria de México en los últimos años de la vigencia de estos programas y en los primeros que siguieron a su cancelación. ${ }^{8}$

En las primeras reuniones interparlamentarias México-Estados Unidos, entre 1961 y 1964, la delegación mexicana, además de reclamar el cumplimiento de las condiciones ofrecidas a los trabajadores mexicanos en materia de salario, salud, vivienda y alimentación, insistió en la necesidad de seguir contando con instrumentos legales binacionales para regular la migración de trabajadores, toda vez que el fenómeno persistiría en la medida que en Estados Unidos hubiera demanda de los servicios de los trabajadores mexicanos.

De manera similar, a la terminación de estos programas, las posiciones de los legisladores mexicanos en las reuniones interparlamentarias de los años siguientes dejan en claro que la delegación mexica-

${ }^{8} \mathrm{El}$ establecimiento, en 1965, de un programa de industrialización fronteriza, que terminó por ser conocido como el programa de la industria maquiladora, fue otro componente de la respuesta gubernamental mexicana para hacerle frente a la terminación de los programas de braceros. Uno de los objetivos del programa era ofrecer una alternativa de empleo a quienes lo solían encontrar migrando regularmente a Estados Unidos. 
na buscaba el restablecimiento de dichos programas. Los eventos que siguieron a 1964 parecieron dar por acertada la previsión hecha por la parte mexicana, en el sentido de que la terminación de estos programas o convenios no impediría la continuidad del flujo de trabajadores mexicanos, simplemente lo volvería subrepticio. En este contexto resulta comprensible que la respuesta mexicana se haya centrado, en un primer momento, en intentar el restablecimiento de algún acuerdo del tipo de los existentes.

En los diez años (1965-1974) que siguen a la cancelación de estos acuerdos, se observa en el discurso de la delegación mexicana en las reuniones interparlamentarias la disposición del gobierno mexicano de satisfacer la demanda estadunidense de mano de obra, siempre mediando la solicitud para ello. La delegación mexicana insiste, hasta 1974 , en la conveniencia para los dos países de establecer nuevamente un acuerdo binacional de contratación legal de trabajadores. Sin embargo, algunos legisladores estadunidenses, asistentes a dichas reuniones, particularmente los representantes de aquellos estados que apoyaban la reanudación de los acuerdos, expresaron que no consideraban la postura mexicana suficientemente decidida. En mi opinión, esta aparente indecisión tiene sus raíces en la tensión que tienden a generar los objetivos que persiguen las delegaciones mexicanas: obtener simultáneamente, por un lado, la seguridad de continuidad legal a un flujo migratorio considerado inevitable y, por otro, la garantía de la defensa de los derechos y las condiciones de trabajo de los migrantes. En principio, los dos objetivos no son irreconciliables; pero en la práctica no eran vistos como complementarios por algunas contrapartes estadunidenses.

\section{La política de la no participación}

Al resultar infructuosos los intentos por restablecer algún programa de tipo bracero, alrededor de 1974-1975 se estructura de manera diferente la estrategia mexicana. ${ }^{9}$ En la segunda mitad de los años setenta se adopta una actitud distante, de aparente falta de involucra-

${ }^{9}$ Como antecedente del cambio de la posición mexicana son interesantes los debates de la Comisión Intersecretarial para el Estudio de los Problemas Derivados de la Corriente Migratoria de Trabajadores Subrepticios Mexicanos a los Estados Unidos, que trabajó en los años 1972-1973. 
miento; parece, incluso, rehuirse una participación directa en el debate y con los responsables estadunidenses sobre el manejo de la cuestión migratoria. ${ }^{10} \mathrm{En}$ los años que siguen, esta posición gubernamental, denominada ulteriormente la política de no tener política, ${ }^{11}$ adquiere un amplio consenso, al menos en los círculos gubernamentales y académicos.

La expresión anterior parece encerrar una contradicción: llamar política a la ausencia de la misma. Ello, sin embargo, no debe conducir a engaño. Por el contrario, uno de los grandes méritos o aciertos de la expresión es llamar la atención sobre el hecho de que se trataba de una postura deliberada, consciente y a tono con los principios de la política exterior mexicana de no intervención en los asuntos internos de otros estados. Específicamente se buscaba prevenir la injerencia de intereses externos -estadunidenses-en asuntos internos mexicanos, como era una presumible vinculación de la cuestión migratoria con el manejo gubernamental en otros ámbitos, en particular en el de la política petrolera (García y Griego, 1988a; Rico, 1992: 228-230).

La expresión anterior revela claramente el carácter funcional de esta política si la postura mexicana se contempla como una estrategia favorable a los objetivos implícitos de la política mexicana acerca de la migración. ${ }^{12}$ Como ya se mencionó, los países de origen de los migrantes excepcionalmente tienen políticas explícitas -como pudiera ser alentar la emigración o impedirla aunque existen casos de lo uno y lo otro de manera permanente o esporádica-; ${ }^{13}$ en todo caso, las más de las veces estas políticas se llevan a cabo calladamente. En el caso mexicano, la estrategia de la no política parece haber permitido el manejo de la cuestión migratoria de manera efectiva, alcanzado "ciertos objetivos relacionados con la migración, sin tener

${ }^{10} \mathrm{En}$ los años formativos de esta posición, es significativa la afirmación de Jorge Bustamante, en el contexto de una propuesta del presidente Carter: "Hasta ahora [marzo de 1978], el gobierno mexicano no ha hecho esfuerzos visibles por formular una política concisa respecto a la emigración de sus ciudadanos" (Bustamante, 1979a: 204). Ig ualmente significativa es la crítica de Víctor L. Urquidi, “... Lo que no se puede hacer es mantenernos a la expectativa y después esperar que los norteamericanos benévolamente tomen medidas que no nos hagan daño." (Urquidi, 1979: 237). 147).

${ }^{11}$ La expresión fue acuñada adecuadamente por Manuel García y Griego (1988a:

12 Por política se entiende la definición de objetivos, metas y medidas; por estrategia se entiende un plan con el fin de alcanzar o lograr un objetivo.

${ }^{13}$ Ciertos países de Asia han mostrado considerable interés en los procesos de emigración, favoreciendo su desenvolvimiento y buscando administrarlos en provecho propio. Véase al respecto Rashid Amjad (1989). 
una política de migración como tal", como se señala en el Informe del Estudio Binacional México-Estados Unidos sobre Migración (Secretaría de Relaciones Exteriores y Commission on lmmigration Reform, 1997: 67).

Los objetivos migratorios en este periodo de la no política no son sustancialmente diferentes de los perseguidos con anterioridad. La existencia de estos objetivos ha sido documentada con precisión para todo el periodo que va de la terminación del programa de braceros, en 1965, a la aprobación de IRCA en 1986. Para Carlos Rico, la política mexicana en ese largo periodo, desde mediados de los años sesenta hasta mediados de los ochenta, tenía dos objetivos principales: primero, prevenir cambios bruscos en la política estadunidense y preservar el flujo migratorio y, segundo, defender los derechos de los migrantes (Rico, 1992: 228-230).

Ante los objetivos anteriores, la estrategia de una baja participación y escaso involucramiento formal tenía sentido y congruencia en función del diagnóstico del momento sobre el fenómeno migratorio y sobre las perspectivas del mismo. El diagnóstico indicaba que la ausencia de un convenio sobre trabajadores temporales - punto de referencia obligado en el momento del cambio- era un factor poco relevante tanto para la continuidad del flujo migratorio como para la defensa de los derechos y las condiciones de trabajo de los migrantes. El discurso de los legisladores mexicanos en las interparlamentarias de esos años no insiste más en la conveniencia de establecer un acuerdo para la contratación de trabajadores. El discurso enfatiza, en cambio, la necesidad de crear empleos en México para arraigar a la población y denuncia las medidas que se debatían en el Congreso estadunidense como represivas e ineficaces para detener el flujo y solucionar de fondo la migración indocumentada.

La estrategia mexicana de no pronunciarse explícitamente por una política específica frente al fenómeno migratorio pareció satisfacer aceptablemente los objetivos e intereses de México. Respecto de la continuidad del flujo, si el número de localizaciones de mexicanos deportables por el Servicio de Naturalización e Inmigración de Estados Unidos es un indicador aceptable de la intensidad de los cruces de personas indocumentadas, el flujo migratorio experimentó continuidad y aumentó durante el periodo de esta estrategia: la cifra de localizaciones de mexicanos deportables pasó de un promedio de 700 mil en los años de 1974 y 1975 a poco más de un millón y cuarto en 1985 (García y Griego y Verea Campos, 1988: 118-121, cuadro 2). Además, las perspectivas sobre el rumbo futuro del fenómeno esta- 
ban determinadas, implícita e indirectamente, por una especie de convencimiento sobre la inevitabilidad de este flujo dadas las fuerzas de demanda y oferta existentes (Alba, 1979), y sobre la conveniencia para Estados Unidos de mantener la condición de ilegalidad del fenómeno migratorio (véase, a manera de ejemplo, Bustamante, 1979b).

De manera similar, a raíz de que se juzgó que los convenios de braceros no garantizaban la salvaguarda de los derechos de los migrantes ni el cumplimiento de las condiciones de trabajo pactadas, el no contar con un acuerdo no se consideró una carencia que impidiera o interfiriera con el objetivo de la protección consular y defensa de los derechos de los migrantes. De hecho, en ese periodo se intensifican las actividades consulares relacionadas con la protección de los migrantes (Gómez Arnau, 1990).

En efecto, un legado trascendente de la política de no tener política de esa época es el énfasis en la protección de los derechos de los trabajadores migratorios, sin importar la condición jurídica de los mismos, sea en el territorio estadunidense o en el cruce de la frontera. En cambio, el objetivo de la continuidad del flujo dejó de ser tema de discusión pública, al menos de manera directa y abierta, y pasó a convertirse en un objetivo implícito.

La no participación y el escaso involucramiento, como estrategia migratoria, tuvieron logros y aciertos importantes tanto desde la perspectiva migratoria como desde la de las relaciones exteriores del país; pero conllevaban también limitaciones. Éstas fueron percibidas por diversos analistas al final del periodo, como se desprende de algunas de las recomendaciones emanadas, frente a legisladores mexicanos, ante la perspectiva de cambios legislativos en Estados Unidos que eventualmente se materializaron en la aprobación de IRCA. Ante un diagnóstico que sostenía el origen binacional del fenómeno se desprendía la necesidad de abordarlo conjuntamente y se recomendaba expresamente que México debía adoptar una postura activa, en el sentido de impulsar la concertación bilateral (Congreso de la Unión, 1985).

Las discusiones y acontecimientos - legislativos y no legislativosen Estados Unidos que condujeron a la aprobación de IRCA provocaron una introspección sobre la política migratoria mexicana cuyo resultado fue el señalamiento de que ésta debía trascenderse. Inmediatamente después de IRCA, Manuel García y Griego lo percibió con gran lucidez: "Si bien en el pasado el balance de una "política de no tener política' pudo haber sido positivo, en años recientes se han 
venido desmoronando las bases que permitieron sostener esa estrategia" (García y Griego, 1988: 147).

\section{La política mexicana posterior a IRCA}

Si en el periodo inmediatamente anterior a IRCA la expresión la polí tica de no tener política refleja acertadamente la esencia de una postura frente al fenómeno migratorio, en la actualidad la expresión la estrategia del diálogo podría ser representativa de la nueva orientación de la posición mexicana. En el contexto de la polémica que tiene lugar en la prensa mexicana a raíz del incidente de Riverside de abril de 1996, la expresión México pierde si no dialoga, parece reflejar de manera explícita la estrategia actual para hacerle frente al fenómeno migratorio. ${ }^{14}$ En un contexto de "conflicto migratorio", el diálogo se presenta como una estrategia, una política para manejar el conflicto, o bien para restringir su área de influencia y los efectos que del mismo pudieran derivarse. La formulación de la estrategia del diálogo es producto fundamentalmente de la administración de Zedillo (19942000), si bien las bases para su sustento se fueron gestando con anterioridad.

\section{La erosión de la politica de la no participación}

Lo primero que se produce es una erosión de la política de no tener política. La Ley de Reforma y Control de la Inmigración (IRCA) en 1986 altera el contexto en el que se da el fenómeno migratorio. ${ }^{15} \mathrm{La}$ aprobación de esta ley equivale al rompimiento de un entendimiento

14 Juan Rebolledo, subsecretario de Asuntos Bilaterales, Secretaría de Relaciones Exteriores (Rebolledo, 1996).

${ }^{15}$ Los elementos principales de IRCA son: la implantación de sanciones a los empleadores que a sabiendas contraten extranjeros no autorizados a residir o a trabajar en dicho país; la continuidad y aprobación de varios programas para atender la demanda de trabajadores - Trabajadores Temporales Agrícolas (H-2-A), Trabajadores Agrícolas Especiales (SAW) y Trabajadores Agrícolas Complementarios (RAW)-; el aumento de recursos a disposición de las agencias de inmigración para ejercer un mayor control de los movimientos en la frontera entre Estados Unidos y México, y el programa de amnistía o regularización de la situación migratoria de quienes hubieran entrado a Estados Unidos antes del 1 de enero de 1982 y residido en ese país desde entonces. 
implícito entre los dos países que había dado lugar al statu quo migratorio que se generó después de la terminación de los convenios sobre trabajadores temporales. Una vez aprobada IRCA, la delegación mexicana, en las Reuniones Interparlamentarias inmediatamente posteriores a 1986, reclama a la estadunidense la unilateralidad y parcialidad -la índole policiaca- de la medida, y en sus intervenciones destacan tres puntos principales: el impacto de la nueva ley sobre los trabajadores migratorios; la imposibilidad de la ley de detener el flujo migratorio y de resolver el problema de fondo, y el interés que existe en el análisis y tratamiento bilaterales de la cuestión migratoria. El propósito restrictivo de IRCA creaba nuevas condiciones que presionaban al gobierno mexicano a reaccionar ante dicha medida, mostrando a la vez las limitaciones de la política de no tener política.

Entre los indicadores de la erosión de la estrategia de no participación ni involucramiento con las contrapartes estadunidenses se encuentran dos acciones de colaboración -claramente novedosasvinculadas con la conducción de las "relaciones migratorias" entre los dos países. Una primera se refiere a las facilidades otorgadas por el gobierno mexicano a la Comisión para el Estudio de la Migración Internacional y el Desarrollo Económico Cooperativo -comisión surgida de la ley IRCA y dependiente del Congreso de Estados Unidospara la realización de sus tareas en territorio nacional. Esta Comisión tenía entre sus mandatos el de establecer consultas con los gobiernos de los países de origen de los migrantes no autorizados-México era nombrado explícitamente- a fin de realizar estudios sobre el fenómeno migratorio no autorizado que sirvieran de base para la elaboración de propuestas dirigidas a modificar el comportamiento del mismo. ${ }^{16}$

El Consejo Nacional de Población (Conapo) fue el organismo encargado de servir de enlace con la Comisión, la cual tuvo reuniones y contactos con otros funcionarios de la Secretaría de Relaciones Exteriores y de Gobernación, con senadores y diputados y con un buen número de miembros de instituciones académicas. Entre las razones que pudieron haber facilitado la decisión mexicana de cola-

${ }^{16}$ Al término de su mandato, la Comisión para el Estudio de la Migración Internacional y el Desarrollo Económico Cooperativo produce el informe Unauthorized Migration: An Economic Development Response, en el que se recomienda, entre otras sugerencias, liberalizar el intercambio comercial entre los dos países como una manera de promover el desarrollo económico de México (Commission for the Study of International Migration and Cooperative Economic Development, 1990). 
borar se ha mencionado que el mandato de la Comisión estaba referido a cuestiones de desarrollo -las condiciones económicas y sociales que generan el fenómeno migratorio y las que podrían contribuir a su disminución-y que la Comisión era dependiente del Congreso de Estados Unidos, no del Poder Ejecutivo. Sin embargo, en lugar preeminente figura la toma de conciencia por parte del gobierno mexicano de que IRCA representaba un cambio de la política de Estados Unidos hacia la migración no autorizada (Weintraub, 1998).

Otro indicador que muestra la erosión de la estrategia de no involucramiento fue la conspicua participación de funcionarios y legisladores mexicanos en la Comisión sobre el Futuro de las Relaciones México-Estados Unidos, un proyecto privado, que trabajó entre 1986 y 1988. Esta comisión tuvo como director ejecutivo mexicano a la directora del Instituto Matías Romero de Estudios Diplomáticos de la Secretaría de Relaciones Exteriores y contó con tres senadores entre los nueve miembros mexicanos. Para esta comisión la cuestión migratoria no fue sino uno de los temas de su mandato, el cual cubría el amplio espectro de las relaciones bilaterales: de la economía al narcotráfico, pasando por la migración. Sobre ese amplio espectro de la relación bilateral, dicha comisión ofreció recomendaciones a ambos gobiernos.

Por lo que respecta al manejo del fenómeno migratorio, habiendo reconocido que un elemento fundamental en la solución de esta cuestión es la reducción de los diferenciales económicos que existen entre ambos países, la Comisión le hacía una serie de recomendaciones al gobierno de México, algunas de las cuales estaban claramente dirigidas a minar la estrategia del pasado. Por su significado se transcriben textualmente las cuatro recomendaciones de esta comisión:

1) Definir con claridad el interés nacional de México en lo que respecta a la migración.

2) Estimular la creación de empleos en las principales regiones de origen de los migrantes, especialmente en las que se considera que la emigración es contraria a los intereses nacionales.

3) Cooperar con las autoridades norteamericanas para asegurar que Estados Unidos cumpla fielmente el convenio de las Naciones Unidas sobre los derechos humanos de los trabajadores migrantes.

4) Colaborar activamente con el gobierno norteamericano en la creación de un enfoque bilateral para las cuestiones de la inmigración (Comisión sobre el Futuro de las Relaciones México-Estados Unidos, 1988: 110). 
Si ante el contexto restrictivo que se desprendía de IRCA una de las reacciones mexicanas fue iniciar un proceso de involucramiento con las contrapartes estadunidenses, entonces la vehemencia de las acciones restrictivas de los años noventa reclamaría con más intensidad continuar y profundizar este involucramiento. ${ }^{17}$ Por un lado, en septiembre de 1993 tiene lugar la Operation Blockade (renombrada poco después Operation Hold-the-Line) en la zona de El Paso, Texas, la cual, como se vería más tarde, fue la primera de una serie de medidas para dificultar la internación clandestina en los cruces fronterizos más frecuentados. En noviembre de 1994 se inicia una acción muy significativa: la Operation Gatekeeper en la zona de San Diego, California. Por otro lado, la discusión de la Propuesta 187 en California durante 1994 se vuelve casi una campaña antinmigrante y antindocumentado mexicano. Esta propuesta fue aprobada por referéndum en California en noviembre de $1994 .{ }^{18}$

Estas dos vías de acción de carácter restrictivo se han ido reforzando y estructurando de manera sistemática en los años siguientes. ${ }^{19}$ Respecto de la encaminada a fortalecer la frontera suroeste de Estados Unidos, se aplicaron medidas como el aumento de personal en operaciones de patrullaje en la frontera, el uso de tecnología sofisticada con fines de detección y la erección de barreras físicas para prevenir el acceso a ese país. La estrategia comenzó concentrando las medidas anteriores en los corredores más frecuentados (San Diego y El Paso), pero se ha ido extendiendo a otros cruces de la línea fronteriza de California a Texas. $\mathrm{El}$ más reciente de estos operativos -la Operación Río Grande- se inició en agosto de 1997 en la parte sur de Texas.

Respecto de la percepción sobre los efectos adversos de los inmigrantes en la economía y sociedad de Estados Unidos -particular-

17 Entre la aprobación de IRCA (1986) y el recrudecimiento posterior de la retórica antindocumentados hay un periodo de relativa calma. Una vez aprobada IRCA, el gobierno y la opinión pública estadunidenses parecen esperar la evaluación de sus efectos. Las discusiones de los años posteriores a IRCA se centran en la política inmigratoria general; proceso que culmina con la Ley de Inmigración de 1990. Además, entre 1989 y 1993, la negociación del TLC descansa en una perspectiva diferente para el control del flujo no autorizado.

${ }^{18}$ La Propuesta 187 busca restringir el acceso de los migrantes a una serie de servicios públicos a fin de alcanzar el doble objetivo de reducir el déficit fiscal estatal y desincentivar el ingreso de inmigrantes que, supuestamente, serían atraídos por la existencia y fácil acceso a numerosos servicios públicos.

${ }^{19}$ La orientación restrictiva de las políticas de inmigración no es privativa de Estados Unidos. Véase al respecto Cornelius, Martin y Hollifield (1994). 
mente en el bienestar, los ingresos y las oportunidades de trabajo de sus ciudadanos y en las finanzas públicas, sean éstas federales, estatales o locales- en 1996 se aprueba la Ley de Reforma de la Inmigración Ilegal y de Responsabilidad del Inmigrante (IIRIRA, por sus siglas en inglés). Con un propósito patentemente restrictivo frente a la inmigración y punitivo frente a los inmigrantes, en particular los no autorizados, esta ley conlleva a aumentar, en general, las penas por violaciones de las estipulaciones legales de inmigración; incrementar los agentes de la patrulla fronteriza y los recursos a su disposición; autorizar la remoción expedita, sin audiencia, a los migrantes no autorizados, a menos que se presente alguna de las pocas causas que permiten una excepción al respecto; restringir la competencia de los tribunales judiciales sobre ciertas decisiones administrativas; incrementar los montos mínimos de ingresos requeridos para los patrocinadores y fiadores de inmigrantes; restringir los beneficios de la seguridad social y los accesos a la educación para los migrantes no autorizados, entre otras disposiciones similares.

Los preceptos de IIRIRA refuerzan los de la Ley de Responsabilidad Personal y Oportunidad Laboral (ley de reforma de la asistencia social), también aprobada en 1996. Esta ley restringe la elegibilidad y el acceso a ciertas categorías de programas de asistencia pública a inmigrantes residentes autorizados pero no ciudadanos y pone límites a la asistencia pública que pueden recibir todos los residentes. En ese año se aprueba también una ley antiterrorista que restringe el ámbito de revisión judicial de las decisiones administrativas, lo que hace más expedito el proceso de deportación de los extranjeros considerados criminales.

Las anteriores acciones e iniciativas estadunidenses provocan reacciones y respuestas por la parte mexicana que ya no se dan dentro del esquema de la política de no tener política. ${ }^{20}$ Las iniciativas se dirigen a contrarrestar el estrechamiento de los derechos de los mexicanos en Estados Unidos. Se utilizan notas diplomáticas de protesta, se negocian acuerdos administrativos en el contexto de las reuniones de la Comisión Binacional (Grupo de Trabajo sobre Migración y Asuntos Consulares) y se firman Memoranda de Entendimiento entre los dos gobiernos. Entre estas reacciones destaca la reforma constitucio-

20 Sobre el modelo analítico de acción y reacción utilizado para entender la conformación de las políticas migratorias en México y en Estados Unidos, véase Weintraub et al. (1998). 
nal de 1996 que permite tener doble (múltiple) nacionalidad a los ciudadanos mexicanos para facilitarles el ajercicio de sus derechos en aquel país. ${ }^{21}$

Desde otra perspectiva, la política migratoria mexicana ha sido fuertemente influida por el Tratado de Libre Comercio de América del Norte (TLCAN o TLC); un tratado que ha cambiado la relación bilateral en su conjunto. El cambio ha sido radical. Todavía a mitad de los años ochenta las relaciones entre los dos países fueron caracterizadas como las que existen entre "vecinos distantes". En los años noventa, en cambio, el discurso y la apreciación sobre las relaciones bilaterales son muy diferentes. Se sostiene que las relaciones entre los dos países, a partir de las administraciones de Salinas y de Bush, se rigen por un "nuevo entendimiento entre socios" (Fernández de Castro, 1997a). El nuevo entendimiento que ha orientado la relación bilateral está marcado por una creciente integración y cooperación entre los socios. La tradicional distancia de México frente a Estados Unidos es sustituida por una política de acercamiento económico y, por ende, político. El emblema por antonomasia de este nuevo entendimiento es, sin lugar a dudas, el TLC. Dada la naturaleza institucional e importancia de este Tratado, sus implicaciones no son sólo comerciales o económicas sino que afectan prácticamente todas y cada una de las cuestiones nacionales.

Las implicaciones del TLC sobre la cuestión migratoria han sido importantes. En un principio, se pensó que México tenía finalmente a su disposición un instrumento que le permitiría abandonar el objetivo de la continuidad del flujo migratorio. La frase de que lo que México desea es exportar bienes y no trabajadores -cuyo equivalente desde la perspectiva estadunidense es comercio en lugar de migración-alcanzó una credibilidad no conocida con anterioridad; credibilidad compartida por los gobiernos de los dos países (Alba, 1993a). En las reuniones parlamentarias de esos años la delegación mexicana expresó que sólo medidas tendentes a reducir la brecha entre ambas economías y a sustentar un crecimiento económico interno -como el TLC- podrían detener los flujos migratorios.

${ }^{21}$ La forma que toma la reforma de los artículos 30,32 y 37 de la Constitución fue hacer irrenunciable la nacionalidad mexicana, excepto en algunos casos. La reforma persigue un doble propósito: por un lado, permitir a sus ciudadanos mantener raíces y contactos con su país de nacimiento $\mathrm{y}$, por otro, eliminar obstáculos que puedan limitar la protección legal y el pleno ejercicio de sus derechos en el país de residencia. 
Una vez que se firmara el TLC las perspectivas del desarrollo nacional se consideraban muy promisorias. Probablemente, por primera vez en la historia contemporánea el modelo económico compartido por el proyecto de integración permitía visualizar la terminación o reducción significativa de la migración como fenómeno masivo. El TLC ofrecía escenarios de convergencia de las economías. Con la liberalización del comercio de bienes y la mayor movilidad del capital se tendería a una asignación más adecuada de los recursos productivos de cada país miembro. En este contexto, un uso más eficiente y pleno del factor trabajo en México produciría un aumento relativo de su precio y, en consecuencia, una reducción de la brecha de ingresos y salarios entre los dos países, lo que disminuiría las presiones migratorias. Los escenarios anteriores provocaron un desbordado optimismo al respecto, al punto que a ambos lados de la frontera hubo necesidad de relativizar los efectos del TLC sobre la evolución del fenómeno migratorio. ${ }^{22}$

Así, aunque parezca paradójico, no hubo propiamente "diálogo migratorio" durante la negociación del TLC - el tema fue vetado sobre la mesa de discusión-, no obstante que se compartía la idea del proyecto de integración económica entre los dos países (y Canadá por extensión) en el sentido de que el desarrollo generado por el TLC impulsaría la convergencia de las economías, lo que haría innecesaria la emigración. Sin embargo, este marco conceptual compartido era poco explícito sobre la evolución y el papel de la demanda como factor determinante de la migración, lo cual resulta poco comprensible dado que el objetivo migratorio transitoriamente compartido fue desincentivar el fenómeno, al menos en una perspectiva de largo plazo.

Los acontecimientos de 1994 y 1995 alteran, sin embargo, los iniciales escenarios optimistas asociados al TLC. ${ }^{23}$ Las perspectivas económicas de México cambian de nuevo profundamente, restando credibilidad a la política comercial como sustituto de la política migratoria. La discusión sobre la evolución futura del fenómeno migratorio vuelve a estar dominada por el conjunto de incentivos económi-

22 Desde un principio se previno que los efectos del TLC sobre las tendencias migratorias no podían ser muy inmediatos ni muy decisivos. A manera de ejemplo véase Alba (1993b); García y Griego (1993); Hinojosa-Ojeda y Robinson (1992).

${ }^{23}$ El 1 de enero de 1994 irrumpe en Chiapas el EZLN, precisamente al entrar en vigor el TLC; durante ese año tienen lugar dos asesinatos políticos y, a fines del mismo, se produce una cuantiosa devaluación del peso. La contracción de la economía es cercana a $7 \%$ en 1995 . 
eos, sociales y demográficos que por largo tiempo han estado operando como un sistema integrado a ambos lados de la frontera. Como en el pasado reciente, la interacción de los factores de demanda y oferta y las redes migratorias vuelven a dar sustento a la idea de ineludibilidad del fenómeno migratorio. ${ }^{24}$ México pierde aproximadamente un cuarto de millón de ciudadanos anualmente en promedio en los años ochenta y alrededor de 300 mil en los noventa. Ante este escenario, "la necesidad" de contar con la "válvula de escape" de la migración para las presiones que se generan sobre la economía y el sistema mexicano en su conjunto vuelve a hacer vigente el tradicional objetivo mexicano de buscar condiciones que permitan la continuidad del fenómeno migratorio.

Las posturas mexicanas en las reuniones interparlamentarias de 1995 a 1997 son refilejo del cambio de actitud, una vez desacreditado el espejismo del TLC. La ampliación de los cauces a la migración documentada, los requerimientos de mano de obra mexicana por parte de Estados Unidos, el establecimiento de un convenio gubernamental entre los dos países, el reconocimiento a la realidad del fenómeno son temas presentes en los debates de esos años.

\section{El diálogo como estrategia}

El nuevo entendimiento que caracteriza las relaciones bilaterales se ha traducido en "una política de diálogo" y en una voluntad de coordinación en los asuntos migratorios durante la administración de Zedillo. De esta manera el TLC ejerce una influencia importante sobre la cuestión migratoria. ${ }^{25}$ En efecto, el proceso de negociación, su aprobación y administración han implicado cambios sustanciales en la densidad y frecuencia de los contactos personales e institucionales de los gobiernos involucrados (incluido el canadiense) y la creación de múltiples instrumentos. Su administràción ha fortalecido los mecanismos e instancias para la consulta, la discusión, la coordinación de decisiones e incluso la solución de controversias. A estos hábitos y actitudes se les ha denominado el "espíritu del TLC", cuya trascen-

\footnotetext{
24 Entrevistado por el diario Reforma, Ángel Gurría, secretario de Relaciones Exteriores, comentó que "No tenemos una perspectiva de que este fenómeno vaya a dejarse de dar" (Gurría, 1996a).

${ }^{25}$ El señalamiento de la influencia del TLC en el manejo de la cuestión migratoria se encuentra presente de manera preeminente en Weintraub et al. (1998).
} 
dencia se ha dejado sentir rápidamente en prácticamente todos los temas de la agenda nacional e internacional de México.

La influencia del TLC sobre la cuestión migratoria no se ha dado en el vacío. La estrategia del diálogo es también una prolongación del acercamiento con las contrapartes estadunidenses en los distintos niveles administrativos de gobierno, lo cual se viene dando a partir de IRCA y se puede ver como una concreción de múltiples reclamos de la parte mexicana -delegados mexicanos en las reuniones interparlamentarias de los años ochenta en adelante e influyentes analistas- por un análisis o perspectiva bilateral del problema. ${ }^{26}$

Entre los antecedentes institucionales de la política del diálogo se cuenta una serie de foros y mecanismos de consulta binacional. Entre ellos destaca el Grupo de Trabajo sobre Migración y Asuntos Consulares, cuyas actividades se iniciaron en 1987 como parte de la Comisión Binacional México-Estados Unidos. Este Grupo de Trabajo se reunió frecuentemente, incluso por separado de la Comisión Binacional, y propuso en marzo de 1994 que los dos gobiernos emprendieran un estudio conjunto sobre el fenómeno migratorio. ${ }^{27}$ La presentación oficial de dicho estudio se hizo, precisamente, en una sesión especial del Grupo de Trabajo sobre Migración y Asuntos Consulares en El Paso, Texas, el 21 de octubre de 1997 (Secretaría de Relaciones Exteriores y Commission on Immigration Reform, 1997).

Otros antecedentes institucionales de la política del diálogo y la voluntad de involucramiento y coordinación se desarrollaron en la zona de la frontera. Los Mecanismos de Enlace Fronterizo fueron creados en 1993 para agilizar la solución de problemas cotidianos en la frontera sin sufrir la demora que probablemente ocurriría de utilizar los canales burocráticos convencionales para tratar las relaciones bilaterales en los ámbitos nacionales correspondientes. Estos Mecanismos de Enlace han desarrollado sus campos de actividad, a partir de su creación en 1993, ${ }^{28}$ en asuntos relacionados con el Servicio de Naturalización e Inmigración de Estados Unidos y con la protección consular de México. Entre sus actividades se encuentran: la coordinación sobre deportaciones; la "facilitación" del cruce fronterizo; el

\footnotetext{
${ }^{26}$ Sobre el enfoque bilateral y la cuestión migratoria véase Bustamante (1988) y García y Griego (1988b).

27 Como antecedente inmediato de esta propuesta se puede citar la realización de un seminario con fines similares en la ciudad de Washington, en octubre de 1993. Véase al respecto, Secretaría de Relaciones Exteriores (1994).

${ }^{28}$ Comunicación personal de Enrique Michel, embajador alterno en Washington.
} 
intercambio de información; las acciones contra el tráfico de migr antes. Un ejemplo adicional de involucramiento es la presencia de funcionarios mexicanos en las actividades de los Grupos Consultivos de Ciudadanos (Citizen's Advisory Panels) estadunidenses en ciudades cercanas a la frontera.

La formulación de la política del diálogo como estrategia consciente y encuadrada en el contexto del espíritu del TLC es, sin embargo, producto de la administración de Zedillo, la primera administración mexicana de la era del TLC. La política del diálogo y la voluntad de coordinación de actividades son una extensión al ámbito migratorio del cambio ocurrido en la relación bilateral en lo comercial y económico principalmente. En esos campos, la relación ha evolucionado del distanciamiento y la confrontación a una actitud pragmática de colaboración en aras de encontrar solución a los problemas derivados de una relación intensificada. La estrategia del diálogo y la coordinación en el ámbito migratorio consiste en el aumento de los contactos gubernamentales en todos los niveles administrativos, en la creación de comisiones de trabajo, la promoción de numerosos acuerdos, el fortalecimiento de los mecanismos de consulta, el intercambio de información, la continua presencia de funcionarios en los foros de discusión, entre otras actividades. ${ }^{29}$ En síntesis, se trata de la intensificación y profundización de las vinculaciones y enlaces interinstitucionales en el ámbito migratorio. ${ }^{30}$

La estrategia de tejer enlaces y vinculaciones durante la administración de Zedillo, se manifiesta también en la promoción y el apoyo de diversos mecanismos regionales y multilaterales de contacto, interacción, diálogo y consulta sobre la cuestión migratoria como fenómeno de carácter regional y global. Entre estos mecanismos conviene anotar la iniciativa de México de organizar un Encuentro Regional sobre Migración; el primero de los cuales se realizó en Puebla en marzo de 1996. Esta instancia reúne a los países de América del Nor-

\footnotetext{
${ }^{29}$ Es sintomático que en la reseña de la comparecencia de confirmación de Jesús Reyes Heroles como embajador de México ante Estados Unidos se coloca la migración, junto con otros temas de la relación bilateral, bajo el encabezado de mecanismo de diálogo y cooperación (Reyes Heroles, 1998).

${ }^{30}$ Estos contactos no se dan tan sólo entre instancias y funcionarios oficiales sino también entre autoridades e instancias privadas. Entre estas últimas, es notoria la participación, en los años de 1994 a 1997, de autoridades mexicanas y estadunidenses del más alto nivel de responsabilidad en materia migratoria en el Grupo Consultivo Estados Unidos-México de Carnegie Endowment for International Peace, en colaboración con El Colegio de México.
} 
te y América Central y tiene visos de institucionalizarse como mecanismo de consulta e intercambio regular de opiniones y propuestas. El Tercer Encuentro Regional sobre Migración tuvo lugar en Ottawa, Canadá, en febrero de 1998, con lo que se consolida el diálogo y la cooperación en materia migratoria en la región.

En este enfoque de diálogo y coordinación parece haber acuerdo entre las dos partes. Al respecto, tal vez la expresión más clara de este entendimiento se encuentra, reveladoramente, en la Declaración Conjunta Adoptada por el Presidente de México y el Presidente de Estados Unidos sobre Migración, el 6 de mayo de 1997, durante la visita del presidente Clinton a México. En esa declaración se afirma que:

Durante los dos últimos años, a través de varios mecanismos, nuestros gobiernos han sostenido consultas e intercambios de información y han alcanzado significativos avances en el tratamiento bilateral de asuntos tales como la protección consular y los derechos humanos de los migrantes, así como los esfuerzos para combatir el tráfico de personas. Este diálogo constructivo representa un primer paso que debe conducir a propuestas específicas para administrar, en beneficio mutuo, la migración entre nuestras naciones [cursivas mías].

La adopción de la política del diálogo representa un cambio trascendente en el manejo de los asuntos migratorios entre los dos países. Con la adopción de esta estrategia, la postura mexicana ha dejado claramente atrás la política de la no política. Sin embargo, el cambio de estrategia no necesariamente conlleva un cambio de objetivos. En la actualidad como en el pasado, el objetivo de la protección de los migrantes es reconocido pública, of icial y abiertamente. Ante la realidad del fenómeno migratorio, "la prioridad es asegurarse de que esa gente [los migrantes] cuente con la protección de sus derechos fundamentales"; en cambio, el objetivo de la continuidad y administración del fenómeno es más controvertido, menos explícito, más escurridizo, si bien se reconoce que es "un fenómeno estructural de nuestra relación con Estados Unidos" (Gurría, 1996a). ${ }^{31}$

${ }^{31}$ En ocasiones parece delinearse un tercer objetivo del gobierno mexicano: el reconocimiento de la contribución de los migrantes a la economía y la sociedad que los recibe. Indicativo de lo anterior es el seminario organizado por el Instituto Nacional de Migración (SG), el Consejo Nacional de Población (SG) y el Instituto Matías Romero de Estudios Diplomáticos (SRE) sobre "Las contribuciones de la inmigración mexicana a la sociedad de Estados Unidos", efectuado el 24 de enero de 1997. 
Sin embargo, la estrategia del diálogo, la coordinación y la cooperación requieren definiciones, posturas concretas y metas específicas. Esta estrategia obliga a tomar decisiones difíciles, ya que el diálogo, por definición, se dirige a algún fin. A raíz de esta nueva postura y actitud mexicana de diálogo, conviene considerar y discutir los efectos e implicaciones de la misma. Entre otras razones porque es comprensible que la estrategia del diálogo cree expectativas que no crearía la estrategia antitética de la política de no tener una política. Ante ese contexto de expectativas no ha transcurrido mucho tiempo y ya se ha elaborado la pregunta: ¿vale la pena esta nueva política? (Fernández de Castro, 1997b).

\section{Algunas implicaciones y consideraciones finales}

En los años que precedieron a IRCA, el reto para los analistas de la política migratoria mexicana era reconciliar lo que aparecía como irreconciliable: ¿cómo alcanzar los objetivos tradicionales de la política mexicana de la defensa de los derechos de los migrantes y la manera de garantizar la continuidad del flujo migratorio con un aparente distanciamiento y un bajo involucramiento gubernamental? La fórmula analítica de la política de la no política tuvo el gran mérito de efectuar esa reconciliación, de resolver esa paradoja. La estrategia del no involucramiento era elemento importante en las condiciones que permitían mantener el statu quo migratorio con el que los dos gobiernos parecían estar satisfechos, ya que ello no les impedía conseguir sus respectivos objetivos nacionales. Es así que esa estrategia o política se juzgó desde la perspectiva mexicana como una opción acertada y, además, compatible con los propósitos más generales de política exterior del país - prevenir la injerencia externa en asuntos internos mexicanos.

El cambio de estrategia -el abandono de la política de no tener política- sugiere que el gobierno mexicano considera que el statu quo previo no existe más y que no está satisfecho con la situación actual. En efecto, el cambio de estrategia -hacia el diálogo- es una señal clara de que el gobierno mexicano está buscando un nuevo entendimiento migratorio con el de Estados Unidos (Fernández de Castro, 1997b). De ser así, surgen preguntas tales como: ¿habría nuevos objetivos a alcanzar en ese nuevo entendimiento?, ¿qué tan efectiva es la nueva estrategia para alcanzar los tradicionales objetivos mexicanos al respecto? 
En cuanto a la primera de las dos preguntas anteriores, surge una primera implicación de la nueva estrategia de diálogo, puesto que la naturaleza de la estrategia misma crea presiones para definir posiciones y objetivos con claridad; precisamente lo contrario de lo que acontecía con la lógica y la estrategia anteriores. Si se dialoga y se está dispuesto a cooperar se debe tener claro sobre qué se dialoga y lo que se persigue. De esa manera, con la nueva política se han observado avances en la definición y discusión de los dos tradicionales objetivos mexicanos.

La situación es más sencilla respecto del objetivo de la protección de los migrantes, que ha sido declarado como el objetivo prioritario de la política mexicana. Durante la política del diálogo se ha reiterado como inalienable e irrenunciable la defensa de este objetivo. ${ }^{32}$ La estrategia del diálogo ha sido efectiva en obtener logros y resultados en este campo, tal vez por la claridad y precisión de lo que se busca con este objetivo.

Es difícil encontrar indicadores confiables y consensualmente aceptados sobre tendencias en el tiempo en materia de protección o violación de los derechos de los migrantes. A pesar de los incidentes y las numerosas muertes ocurridos en la frontera, la impresión generalizada es que, sin embargo, en el contexto de la política de diálogo se han obtenido logros importantes respecto de esta materia. El compromiso de fomentar el respeto a los derechos humanos de los migrantes forma ya parte explícita de compromisos firmados por los dos gobiernos en los niveles de gabinete y presidencial. ${ }^{33}$ Entre las acciones concretas se pueden anotar la facilitación del desempeño de las funciones consulares - como notificación de sus derechos a los migrantes detenidos, acceso a las representaciones consulares o presencia de funcionarios consulares en los procesos judiciales-, la me-

32 "[...] asumimos como nuestro deber indeclinable proteger la integridad y los derechos humanos y laborales de nuestros connacionales. Su condición migratoria no altera sus derechos inalienables como seres humanos [...] invariablemente solicitaremos, con igual firmeza que respeto, la identificación y sanción de quienes lastimen sus derechos, así como la reparación de los daños". Angel Gurría, "México-Estados Unidos: la construcción de una colaboración intensa y libre de condicionamientos", Ceremonia Inaugural de la XIII Reunión de la Comisión Binacional México-Estados Unidos, México, D.F., 6 de mayo de 1996 (Gurría, 1996b: 15-16).

33 Véase el Memorándum de Entendimiento sobre Protección Consular de Nacionales de Estados Unidos y México, mayo de 1996 y la Declaración Conjunta Adoptada por el Presidente de México y el Presidente de Estados Unidos sobre Migración, en mayo de 1997. 
joría en la coordinación de las deportaciones, intercambio de información y una colaboración más estrecha en la lucha contra los traficantes de migrantes, entre otros aspectos.

La situación no es, en cambio, tan sencilla respecto del objetivo, todavía implícito, de la prevención de cambios abruptos en la política inmigratoria estadunidense y en el flujo migratorio mismo. Respecto de la implicación del cambio de estrategia en el sentido de forzar definiciones y posturas concretas al respecto, los resultados no son fácilmente visibles. Hasta ahora lo que se observa es una posición oficial de cautela y reflexión que, sin embargo, trasluce que dicho objetivo es motivo de discusión y consideración. La emigración de mexicanos no ha sido promovida en el pasado ni lo es en la actualidad. Sin embargo, de la consideración -casi neutral- de la inevitabilidad del fenómeno parece estar pasándose a una posición que busca una legalidad asociada a dicha inevitabilidad. Esta búsqueda se deja entrever en los pronunciamientos de altos funcionarios sobre la deseabilidad y urgencia de un manejo conjunto o bilateral del fenómeno migratorio. ${ }^{34}$ Una de las interpretaciones del "manejo conjunto" del fenómeno migratorio es llegar a un acuerdo o tratado migratorio similar o no con los acuerdos previos de trabajadores temporales, lo que da lugar a discusiones sobre la clase de acuerdo que se desea. Al respecto, el Informe del Estudio Binacional México-Estados Unidos sobre Migración adoptó una propuesta muy cautelosa al alentar el "análisis de la conveniencia de un programa bilateral de trabajadores extranjeros México-Estados Unidos, con el debido reconocimiento de que es improbable que tal programa sea un remedio eficaz de la migración no autorizada" (Secretaría de Relaciones Exteriores y Commission on Immigration Reform, 1997:81).

Sin embargo, lo que a nivel gubernamental es implícito, a nivel de opinión pública no lo es tanto. Así, algunas de las expresiones más concretas relacionadas con el objetivo de asegurar una apertura al trabajo mexicano provienen de agentes políticos fuera del gobierno, quienes, sobre todo a partir de la negociación del TLC, exigen al gobierno obtenga la apertura de las fronteras al trabajador mexicano, cuestionan el sesgo de la liberalización contenido en el acuerdo del TLC -ésta se aplica a los bienes y al capital, mas no al trabajo-y, por lo mismo, piden incorporar o incluir el tema migratorio en una

34 "Lo que estamos buscando desde el principio [de la administración] es un enfoque bilateral" (Gurría, 1997). 
especie de TLC ampliado. Es sintomático que en los medios de información parezca ganar receptividad la idea de explorar y llegar a establecer algún acuerdo del tipo bracero. Se está produciendo también una especie de politización de la cuestión migratoria, lo que afecta indudablemente la postura gubernamental que se ve forzada a reaccionar ante un debate llevado ante la opinión pública. ${ }^{35}$

En comparación con los logros obtenidos respecto del objetivo del respeto de los derechos de los migrantes, aunque el filujo continúa, el objetivo de asegurar o acordar su continuidad no ha obtenido satisfacción con la estrategia del diálogo y la cooperación. Es revelador lo atribuido al secretario de Relaciones Exteriores: "En el caso de la migración no hemos logrado desarrollar un concepto bilateral, un concepto compartido del objetivo último" (Gurría, 1997).

Dado que el diálogo implica negociación -dar y recibir-, una de las principales implicaciones de la estrategia del diálogo es la necesidad de articular una posición concreta respecto de la consecución de algún acuerdo migratorio o la aceptación de no contar con ninguno. Éste es tal vez el reto inmediato más importante de la política mexicana frente al fenómeno migratorio, contenido en la Declaración de los Presidentes de mayo de 1997, cuando suscriben la idea de que el diálogo "representa un primer paso que debe conducir a propuestas especificas para administrar, en beneficio mutuo, la migración entre nuestras naciones" [cursivas mías].

Desde esta perspectiva, el reto es doble: por un lado, promover la reflexión y la discusión sobre opciones y alternativas, sopesar las que sostienen los diversos agentes sociales - los partidos, las ONG, etc.- y se debaten entre la opinión pública; por otro, alcanzar la conformación de un consenso respecto al objetivo relacionado con el flujo migratorio y la negociación de la cuestión migratoria. Este doble reto se puede volver una de las implicaciones más difíciles de soslayar, ya que las probabilidades de una negociación aumentan con la estrategia del diálogo. La negociación es su desenlace lógico; sin ella la institucionalización del diálogo terminará por agotarse y la política del diálogo no materializará su potencial constructivo. El riesgo es elevado, ya que el contexto institucional que rige la relación bilateral está dominado por un enfoque sectorial -cuyo instrumento es el TLC- en el cual el comercio es contemplado como sustituto de la migración.

\footnotetext{
${ }^{35}$ Esta politización de la cuestión migratoria es influida también por los procesos de pluralidad política y apertura cívica experimentados en el país en años recientes.
} 


\section{Bibliografia}

Alba, Francisco (1979), "Industrialización sustitutiva y migración internacional: el caso de México", en Centro de Estudios Internacionales, Indocumentados: mitos y realidades, México, El Colegio de México, pp. 1-21.

(1993a), "La migración mexicana a Estados Unidos y la iniciativa del Tratado de Libre Comercio: el juego de las expectativas", en Gustavo Vega (ed.), Liberación económica y libre comercio en América del Norte: consideraciones políticas, sociales y culturales, México, El Colegio de México, pp. 273-289.

(1993b), "El Tratado de Libre Comercio y la emigración de mexicanos a Estados Unidos", Comercio Exterior, vol. 43, núm. 8, pp. 743-749.

Amjad, Raschid (ed.) (1989), To the Gulf and Back. Studies on the Economic Impact of Asian Labour Migration, Nueva Delhi, United Nations Development Program and International Labour Organization.

Bustamante, Jorge A. (1979a), "Las propuestas de política migratoria en los Estados Unidos y sus repercusiones en México", en Centro de Estudios Internacionales, Indocumentados: mitos y realidades, México, El Colegio de México, pp. 197-208.

(1979b), "Emigración indocumentada a los Estados Unidos", en Centro de Estudios Internacionales, Indocumentados: mitos y realidades, México, El Colegio de México, pp. 23-60

(1988), "U.S. Immigration Reform: A Mexican Perspective", en Susan Kaufman Purcell (ed.), Mexico in Transition; Implications for the U.S. Policy; Essays from Both Sides of the Border, Nueva York, Council on Foreign Relations, pp. 69-80.

Comisión sobre el Futuro de las Relaciones México-Estados Unidos (1988), El desafio de la interdependencia: México y Estados Unidos, México, Fondo de Cultura Económica.

Commission for the Study of International Migration and Cooperative Economic Development (1990), Unauthorized Migration: An Economic Development Response, Washington, julio.

Congreso de la Unión (1985), "Audiencia Pública del Senado sobre Trabajadores Migratorios”, Diario de los Debates, t. 1, núm. 28, Cámara de Senadores del Congreso de los Estados Unidos Mexicanos.

(varios años), Memorias de las Reuniones Interparlamentarias, México.

Cornelius, Wayne A., Philip L. Martin y James F. Hollifield (eds.) (1994), Controlling Immigration. A Global Perspective, Stanford, Stanford University Press.

Fernández de Castro, Rafael (1997a), "Perspectivas teóricas en los estudios de la relación México-Estados Unidos: el caso de la cooperación intergubernamental", en La política exterior de México. Enfoques para su análisis, México, El Colegio de México/Instituto Matías Romero de Estudios Diplomáticos, pp. 45-68. 
(1997b), "The Mexican Government's Position on Migration: From Non-Engagement to an Active Search for a New Understanding. Is it Worth it?", en Immigration in U:S.Mexican Relations, Washington, Brookings Institution, pp. 33-37.

(1998), "The Riverside Incident", en Mexico-United States Binational Migration Study, Migration Between Mexico and the United States, vol. 3, Austin, pp. 1235-1240.

García y Griego, Manuel (1988a), "Hacia una nueva visión del problema de los indocumentados en Estados Unidos", en Manuel García y Griego y Mónica Verea Campos, México y Estados Unidos frente a la migración de los indocumentados, México, Coordinación de Humanidades, UNAM/Miguel Ángel Porrúa, pp. 123-152.

(1988b), "A Bilateral Approach to Migration Control?", en Susan Kaufman Purcell (ed.), Mexico in Transition; Implications for the U.S. Policy; Essays from Both Sides of the Border, Nueva York, Council on Foreign Relations, pp. 81-91.

(1993), "La emigración mexicana y el Tratado de Libre Comercio en América del Norte: dos argumentos", en Gustavo Vega (ed.), Liberación económica y libre comercio en América del Norte, México, El Colegio de México, pp. 291-304.

(1998), "The Bracero Program", en Mexico-United States Binational Migration Study, Migration Between Mexico and the United States, vol. 3, Austin, pp. 1215-1221.

y Mónica Verea Campos (1988), "Migración de trabajadores mexicanos a Estados Unidos", en Manuel García y Griego y Mónica Verea Campos, México y Estados Unidos frente a la migración de los indocumentados, México, Coordinación de Humanidades, UNAM/Miguel Ángel Porrúa, pp. 49-121.

Gómez Arnau, Remedios (1990), México y la protección de sus nacionales en Estados Unidos, México, CISEUA, UNAM.

Gurría, Ángel (1996a), "La entrevista", Reforma, entrevista de Raymundo Riva Palacio y Ciro Gómez Leyva, 12 de abril, p. 4A.

(1996b), "México-Estados Unidos: la construcción de una colaboración intensa y libre de condicionamientos", en Secretaría de Relaciones Exteriores, Discursos del Secretario de Relaciones Exteriores, Ángel Gurría, México, SRE, mayo-junio, pp. 11-17.

(1997), "Divergencias con Estados Unidos sobre migración, reconoce México", El Financiero, nota informativa, 5 de mayo, p. 52.

Hinojosa-Ojeda, Raúl y Sherman Robinson (1992), "Labour Issues in a North American Free Trade Area", en Nora Lustig, Barry O. Bosworth y Robert Z. Lawrence (eds.), North American Free Trade. Assesing the Impact, Washington, The Brookings Institution, pp. 69-98.

México, Leyes (1996), Ley General de Población y Reglamento de la Ley General de Población, México, Secretaría de Gobernación. 
Rebolledo, Juan (1996), "México pierde si no dialoga", Reforma, entrevista de Dulce Ruiz de Chávez, 3 de mayo, p. 4A.

Reyes Heroles, Jesús (1998), "Mexico and United States at the End of the Millenium", Voices of Mexico, núm. 42, pp. 51-54.

Rico, Carlos (1992), "Migration and U.S.-Mexican Relations 1966-1986", en Christopher Mitchell (ed.), Western Hemisphere Immigration and United States Foreign Policy, Pennsylvania, The Pennsylvania State University Press, pp. 221-283.

Secretaría de Relaciones Exteriores (1994), La migración laboral mexicana a Estados Unidos de América: una perspectiva bilateral desde México, México, SRE.

y Commission on Immigration Reform (1997), Informe del Estudio Binacional México-Estados Unidos sobre Migración, México, SRE.

Urquidi, Víctor L. (1979), "Comentario final", en Centro de Estudios Internacionales, Indocumentados: mitos y realidades, México, El Colegio de México, pp. 229-238.

Weintraub, Sidney (1998), "IRCA and the Facilitation of U.S.-Mexico Migration Dialogue", en Mexico-United States Binational Migration Study, Migration Between Mexico and the United States, vol. 3, Austin, pp. 1229-1233.

, Francisco Alba, Rafael Fernández de Castro y Manuel García y Griego (1998), "Responses to Migration Issues", en Mexico-United States Binational Migration Study, Migration Between Mexico and the United States, vol. 1, Austin, pp. 437-509. 
